\title{
BIOMASSA, NUTRIENTES E METAIS PESADOS EM RAÍZES DE EUCALIPTOS ADUBADOS COM DIFERENTES LODOS DE ESGOTO
}

\author{
Alexandre de Vicente Ferraz ${ }^{1 *}$, Fábio Poggiani ${ }^{1}$
}

*Autor para correspondência: avferraz@usp.br

RESUMO: O uso de lodo de esgoto em plantações florestais tem sido incentivado em vários países por favorecer o crescimento das árvores. Todavia, a eventual presença de metais pesados em alguns lodos tem tornado mais frequente seu descarte em aterros sanitários. Neste trabalho, objetivou-se avaliar a biomassa seca, a concentração de nutrientes e metais pesados em raízes finas $(\varnothing<5$ $\mathrm{mm}$ ) de árvores de Eucalyptus grandis adubadas com lodos de diferentes estações de tratamento de esgotos (ETEs). O delineamento experimental utilizado foi em blocos, casualizado, com 4 repetições e 5 tratamentos: (1) Testemunha, sem qualquer adubação; (2) Fertilização mineral NPK e (3, 4 e 5) Adubação com $15 \mathrm{t} \mathrm{ha}^{-1}$ (base seca) de lodo de esgoto oriundo das estações de tratamento de Barueri-SP, São Miguel-SP e Parque Novo Mundo-SP, respectivamente. As amostras de raízes finas foram coletadas aos 42 meses de idade das árvores, na camada de $0-20 \mathrm{~cm}$ da superfície do solo, por meio de uma sonda de aço inox. Nessa fase, a biomassa de raízes finas foi similar entre os tratamentos com lodo de esgoto e a testemunha. Mas, a adubação com o lodo da ETE Parque Novo Mundo, condicionado com cal, propiciou maior biomassa de raízes em relação à fertilização mineral. De maneira geral, a adubação com os lodos de diferentes ETEs elevou a concentração de $\mathrm{P}, \mathrm{Ca}, \mathrm{Zn}$ e Ni nas raízes finas de E. grandis e reduziu a concentração de $\mathrm{Mn}$, mas não alterou significativamente a concentração dos metais $\mathrm{Cd}, \mathrm{Cr}$ e $\mathrm{Pb}$.

Palavras-chave: biossólido, Eucalyptus grandis, raízes finas.

\section{BIOMASS, NUTRIENT AND HEAVY METAL IN EUCALYPTUS ROOTS FERTILIZED WITH DIFFERENT SEWAGE SLUDGE}

\begin{abstract}
The application of sewage sludge in forestry plantations has been encouraged in several countries for promoting growth of trees. However, because the sludge eventually contains heavy metals, it has been disposed frequently in landfills. This study investigated the biomass and the concentration of nutrients and heavy metals in fine roots $(\varnothing<5 \mathrm{~mm})$ of Eucalyptus grandis trees fertilized with sludges from different wastewater treatment plants (WTPs). The experimental design comprised randomized blocks with four replications and five treatments: (1) control, without fertilization, (2) mineral fertilization NPK and (3, 4 and 5) Fertilization with $15 \mathrm{tha}^{-1}$ (dry basis) of sewage sludge from Barueri-SP, São Miguel-SP and Parque Novo Mundo-SP wastewater treatment plants. Samples of fine roots were collected at 42 months old of trees, at layer 0-20 cm of soil, using a stainless steel probe. In this stage, the fine root biomass was similar among treatments with sewage sludge and the control. However, the soil fertilization with sewage sludge from Parque Novo Mundo WTP, conditioning with lime, provided higher root biomass than mineral fertilization. In general, the soil fertilization with sewage sludge from different WTPs increased the concentration of $P, C a, Z n$ and Ni in the fine roots of E. grandis and reduced the Mn concentration, but don't significantly changed the concentration of the $\mathrm{Cd}, \mathrm{Cr}$ and $\mathrm{Pb}$.
\end{abstract}

Keywords: biosolids, Eucalyptus grandis, fine root.

\section{INTRODUÇÃO}

Em decorrência da poluição provocada pelo lançamento de esgotos in natura em cursos d'água, estações de tratamento de esgoto (ETEs) vêm sendo implementadas nas principais cidades brasileiras, obtendo-se, geralmente, considerável redução da carga orgânica dos efluentes (BOEIRA et al., 2002).

Entretanto, como resultado final do processo de tratamento do esgoto há sempre a geração de um novo resíduo denominado lodo de esgoto ou biossólido (BORGES; COUTINHO, 2004), cuja disposição final por meios convencionais (e.x. aterros sanitários, lagos e oceano) representa um alto custo para as empresas de saneamento básico, além de ser ecologicamente inadequada (OLIVER et al., 2005).

Em muitos casos, os lodos carregam consigo significativa parcela do potencial poluidor dos esgotos dos quais se originaram e, portanto, apresentam teores variáveis de substâncias (e.x. metais pesados) que podem ser prejudiciais ao meio ambiente (ASSUNÇÃO; SÍGOLO, 1997).

Atualmente, a disposição do lodo de esgoto em plantios florestais, como fertilizante e condicionador do solo, tem se apresentado como uma das alternativas mais promissoras, tendo em vista os benefícios atribuídos

1 Universidade de São Paulo - Piracicaba, São Paulo, Brasil

Cerne, Lavras, v. 20, n. 2, p. 311-320, abr./jun. 2014 
à reciclagem de nutrientes (VEGA et al., 2004) e o incremento da produção de madeira, sem afetar a cadeia alimentar humana (MAGESAN; WANG, 2003).

Em razão das características de rápido crescimento e sistema radicular bastante desenvolvido, o eucalipto tem evidenciado uma elevada capacidade de absorção dos nutrientes, bem como de metais pesados eventualmente disponíveis no solo (SOARES et al., 2000). Esses elementos (e.x. cromo, cádmio e chumbo), ao serem absorvidos pelas plantas, acabam sendo acumulados em maior quantidade nas raízes, pois tendem a se ligar aos sítios de troca dos compostos ativos presentes na parede celular do tecido radicular (KABATA-PENDIAS; PENDIAS, 2001).

Apesar de sua importância, o acúmulo de nutrientes e metais pesados em raízes de eucaliptos tem sido pouco estudado, em razão principalmente, da dificuldade de mensuração (ROBINSON, 2007). Aliás, a maioria dos estudos realizados com raízes trata apenas do sistema radicular de sustentação (WITSCHORECK et al., 2003); sendo que, do ponto de vista funcional, as raízes finas são aquelas que apresentam intensa atividade metabólica, tendo como principal atribuição fisiológica a absorção de água e nutrientes (GONÇALVES; MELLO, 2005).

Portanto, a adubação de plantios florestais com lodo de esgoto pode contribuir para aumentar a produção de biomassa arbórea (ex. tronco) (ROCHA et al., 2004), bem como, elevar a concentração de nutrientes (GUEDES et al., 2006) e metais pesados nos tecidos vegetais. Conduziu-se este trabalho com o objetivo de avaliar a biomassa de raízes finas em plantios de Eucalyptus grandis adubados com lodos de esgoto produzidos por diferentes ETEs, além de determinar a concentração de nutrientes e metais pesados nas raízes finas das árvores.

\section{MATERIAL E MÉTODOS}

O estudo foi realizado na Estação Experimental de Ciências Florestais de Itatinga (EECFI), pertencente a USP e localizada na região centro-sul do estado de São Paulo. A EECFI encontra-se no município de Itatinga-SP, nas coordenadas $23^{\circ} 10^{\prime} \mathrm{S}$ e $48^{\circ} 40^{\prime} \mathrm{W}$, a $860 \mathrm{~m}$ de altitude.

De acordo com a classificação Köppen, o clima da região é do tipo Cwa - mesotérmico úmido com inverno seco. A precipitação média anual é de $1300 \mathrm{~mm}$, ocorrendo à maior incidência de chuvas no período de outubro a março. A temperatura média anual é de $19,4^{\circ} \mathrm{C}$, sendo a mínima de $16,3^{\circ} \mathrm{C}$ no mês de julho e a máxima de $21,9^{\circ} \mathrm{C}$ no mês de janeiro.

O solo foi classificado como Latossolo Vermelho Amarelo distrófico típico, A moderado, com textura média (EMPRESA BRASLEIRA DE PESQUISA AGROPECUÁRIA - EMBRAPA, 2006). A baixa fertilidade do solo (Tabela 1) e o relevo plano do local de estudo representaram as condições características da maioria das áreas florestadas com o gênero Eucalyptus no estado de São Paulo.

Tabela 1 - Atributos químicos e físicos do solo antes da instalação do experimento.

Table 1 - Chemical and physical attributes of soil before the experiment.

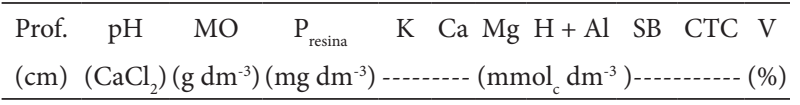

\begin{tabular}{|c|c|c|c|c|c|c|c|c|c|}
\hline $0-5$ & 3,6 & 47 & 4 & 0,7 & 2 & 1 & 68 & 3,4 & 71,4 \\
\hline $5-20$ & 3,8 & 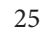 & 2 & 0,4 & 1 & 1 & 49 & 2,4 & 51,0 \\
\hline-40 & 3 & & 1 & 2 & 1 & 1 & 41 & 2,2 & 43,2 \\
\hline Prof. & B & $\mathrm{Cu}$ & $\mathrm{Fe}$ & $\mathrm{Mn}$ & Zn & \multicolumn{2}{|c|}{ Areia total } & Silte & $\begin{array}{c}\text { Argila } \\
\text { total }\end{array}$ \\
\hline$(\mathrm{cm})$ & \multicolumn{9}{|c|}{ - $\left(\mathrm{mg} \mathrm{dm}^{-3}\right)$} \\
\hline $0-$ & 0 , & 3,6 & 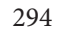 & 1,8 & 0,3 & & 81 & 4,0 & 15,0 \\
\hline $5-20$ & 0,2 & 2,2 & 103 & 0,7 & 0,2 & & 78 & 4,0 & 18,0 \\
\hline $20-40$ & 0,1 & 1,1 & 63 & 0,5 & 0,1 & & 78 & 4,0 & 18,0 \\
\hline
\end{tabular}

${ }^{*}$ Análise química realizada segundo metodologia apresentada por Raij et al. (1987)

**Análise física realizada segundo metodologia proposta por Camargo et al. (1986)

O povoamento experimental de eucaliptos foi implantado em maio de 2005, com mudas produzidas em tubete pelo viveiro da Cia. Suzano de Papel e Celulose, a partir de sementes oriundas de uma única progênie de Eucalyptus grandis. O solo foi preparado com subsolagem até a profundidade de $40 \mathrm{~cm}$ e o espaçamento de plantio foi de 3 metros entre linhas e 2 metros entre plantas. O delineamento experimental foi em blocos, com parcelas aleatorizadas e 4 repetições. Cada parcela foi composta por 100 plantas, totalizando $600 \mathrm{~m}^{2}$; entretanto, como se utilizou bordadura dupla, a área útil de cada parcela foi de $216 \mathrm{~m}^{2}$, constituída por 36 árvores.

Os tratamentos foram: 1) Testemunha, sem qualquer adubação (T); 2) Fertilização mineral, praticada pelas empresas florestais da região (FM); 3) $15 \mathrm{t} \mathrm{ha}^{-1}$ (base seca) de lodo da ETE de Barueri (LB); 4) $15 \mathrm{t} \mathrm{ha}^{-1}$ (base seca) de lodo da ETE de São Miguel (LS) e 5) $15 \mathrm{t} \mathrm{ha}^{-1}$ (base seca) de lodo da ETE do Parque Novo Mundo (LP), todas da região metropolitana de São Paulo. Na implantação

Cerne, Lavras, v. 20, n. 2, p. 311-320, abr./jun. 2014 
do experimento, a quantidade e a forma de aplicação dos lodos ao solo foram efetuadas de acordo com estudos prévios (GUEDES et al., 2006) e critérios estabelecidos pela norma P 4.230 (COMPANHIA DE TECNOLOGIA DE SANEAMENTO AMBIENTAL - CETESB, 1999).

Os lodos de esgoto produzidos nas ETEs de Barueri e São Miguel foram condicionados com polieletrólito, ao passo que o lodo da ETE do Parque Novo Mundo foi condicionado com $\mathrm{CaO}$ e $\mathrm{FeCl}_{3}$. Com isso, os lodos apresentaram características químicas distintas entre si, conforme se observa na Tabela 2.

Vale ressaltar que a expressiva concentração de cálcio $(\mathrm{Ca})$ no lodo produzido pela ETE de São Miguel ocorreu em razão do despejo de resíduos industriais, à base de sulfato de cálcio, na rede de esgoto; enquanto que, na ETE Parque Novo Mundo, a acentuada concentração de cálcio no lodo ocorreu em decorrência de seu condicionamento com cal.

Além do lodo de esgoto, foram aplicados nos tratamentos LB, LS e LP: $100 \mathrm{~kg} \mathrm{ha}^{-1}$ do fertilizante NPK (6:30:6) e $80 \mathrm{~kg} \mathrm{ha}^{-1}$ de FTE BR $12(9 \% \mathrm{Zn}+1,8 \% \mathrm{~B}+$ $0,8 \% \mathrm{Cu}+2 \% \mathrm{Mn}+3,5 \% \mathrm{Fe}+0,1 \% \mathrm{Mo}$ ), ambos como adubação pré-plantio das mudas, e $100 \mathrm{~kg} \mathrm{ha}^{-1}$ de $\mathrm{KCl}$ aplicado aos 3 e 6 meses pós-plantio. A aplicação dos lodos de esgoto foi efetuada em uma faixa de aproximadamente $50 \mathrm{~cm}$ de largura, sobre a superfície do solo, nas linhas de plantio. Além disso, os lodos foram aplicados um mês antes do plantio das mudas, buscando minimizar possíveis danos às plantas de E. grandis devido à volatilização de amônia do lodo de esgoto.

No tratamento FM, foram aplicados ao solo: $1,5 \mathrm{t}$ ha $^{-1}$ de calcário dolomítico (PRNT $=85 \%, \mathrm{CaO}=37 \%$ e $\mathrm{MgO}=16 \%) ; 200 \mathrm{~kg} \mathrm{ha}^{-1}$ de NPK (6:30:6) e $80 \mathrm{~kg} \mathrm{ha}^{-1} \mathrm{de}$ FTE BR 12, ambos como adubação pré-plantio, e $200 \mathrm{~kg}$ ha $^{-1}$ de NPK (18:6:24), aplicados aos 3, 6 e 9 meses pósplantio em forma de coroa ao redor de cada muda.

A coleta das amostras de raízes finas foi realizada aos 42 meses de idade das árvores de $E$. grandis, quando o volume de madeira acumulado por tratamento era: $\mathrm{T}=53,8$ $\mathrm{m}^{3} \mathrm{ha}^{-1} ; \mathrm{FM}=104,6 \mathrm{~m}^{3} \mathrm{ha}^{-1} ; \mathrm{LB}=107,2 \mathrm{~m}^{3} \mathrm{ha}^{-1} ; \mathrm{LS}=96,4$ $\mathrm{m}^{3} \mathrm{ha}^{-1} \mathrm{e} \mathrm{LP}=88,1 \mathrm{~m}^{3} \mathrm{ha}^{-1}$. Nessa fase, foram coletadas nas linhas de plantio 30 amostras de "terra+raízes" por parcela, entre 0-20 cm de profundidade do solo; correspondendo, portanto, à coleta de uma amostra de raízes por $\mathrm{m}^{2}$ de lodo aplicado ao solo. Para isso, foi utilizada uma sonda de aço inox com $3 \mathrm{~cm}$ de diâmetro e $80 \mathrm{~cm}$ de altura.

As amostras de raízes foram agrupadas por parcela e lavadas em água corrente sobre um conjunto de peneiras sobrepostas, cujas malhas variaram de 2,19 a $0,84 \mathrm{~mm}$. Após a lavagem e a eliminação das partículas de solo, as raízes retidas nas peneiras foram encaminhadas ao laboratório para a remoção de impurezas.

No laboratório, as raízes foram banhadas sequencialmente em cinco soluções: $1^{\text {a }}$ - solução de água com detergente, para solubilização das partículas de solo; $2^{\mathrm{a}}$ - água destilada, para a eliminação do detergente aderido à amostra; $3^{\mathrm{a}}$ - solução de EDTA a $0,5 \%$, para a retirada dos íons adsorvidos à superfície das raízes; $4^{\mathrm{a}} \mathrm{e}$

Tabela 2 - Atributos químicos dos lodos de esgoto produzidos em 2005 pelas estações de tratamento de esgoto (ETEs): Parque Novo Mundo, São Miguel e Barueri.

Table 2 - Chemical attribute of the sewage sludge produced in 2005 by wastewater treatment plants (ETEs, by acronym in Portuguese) of the Parque Novo Mundo, São Miguel and Barueri.

\begin{tabular}{|c|c|c|c|c|}
\hline \multirow{2}{*}{ Atributos } & \multirow{2}{*}{ Un. } & \multicolumn{3}{|c|}{$\begin{array}{c}\text { Estação de Tratamento de } \\
\text { Esgoto }\end{array}$} \\
\hline & & $\begin{array}{l}\text { Parque N. } \\
\text { Mundo }\end{array}$ & $\begin{array}{c}\text { São } \\
\text { Miguel }\end{array}$ & Barueri \\
\hline $\mathrm{pH}$ em $\mathrm{CaCl}_{2}$ a $0,01 \mathrm{M}$ & - & 8,2 & 7,6 & 7,7 \\
\hline Umidade $_{\text {total }}$ & $\mathrm{g} \mathrm{kg}^{-1}$ & 67,17 & 71,32 & 81,59 \\
\hline Matéria Orgânica ${ }_{\text {total }}$ & $\mathrm{g} \mathrm{kg}^{-1}$ & 506,5 & 538,4 & 557,8 \\
\hline Nitrogênio $_{\text {total }}$ & $\mathrm{g} \mathrm{kg}^{-1}$ & 17,1 & 16,4 & 36,9 \\
\hline Fósforo $\left(\mathrm{P}_{2} \mathrm{O}_{5}\right)_{\text {total }}$ & $\mathrm{g} \mathrm{kg}^{-1}$ & 28,9 & 24,8 & 44,5 \\
\hline Potássio $\left(\mathrm{K}_{2} \mathrm{O}\right)_{\text {total }}$ & $\mathrm{g} \mathrm{kg}^{-1}$ & 1,2 & 1,4 & 2,2 \\
\hline Cálcio $(\mathrm{Ca})_{\text {total }}$ & $\mathrm{g} \mathrm{kg}^{-1}$ & 112,4 & 108,4 & 27,7 \\
\hline Magnésio $(\mathrm{Mg})_{\text {total }}$ & $\mathrm{g} \mathrm{kg}^{-1}$ & 3,4 & 1,7 & 4,3 \\
\hline Enxofre $(S)_{\text {total }}$ & $\mathrm{g} \mathrm{kg}^{-1}$ & 6,1 & 6,6 & 6,5 \\
\hline Cobre $(\mathrm{Cu})_{\text {total }}$ & $\mathrm{mg} \mathrm{kg}^{-1}$ & 457 & 66 & 858 \\
\hline Manganês $(\mathrm{Mn})_{\text {total }}$ & $\mathrm{mg} \mathrm{kg}^{-1}$ & 289 & 328 & 369 \\
\hline Zinco $(\mathrm{Zn})_{\text {total }}$ & $\mathrm{mg} \mathrm{kg}^{-1}$ & 1.130 & 429 & 3.026 \\
\hline Ferro $(\mathrm{Fe})_{\text {total }}$ & $\mathrm{mg} \mathrm{kg}^{-1}$ & 82.574 & 34.878 & 42.401 \\
\hline Boro (B) ${ }_{\text {total }}$ & $\mathrm{mg} \mathrm{kg}^{-1}$ & 6 & 3 & 16 \\
\hline Cádmio $(\mathrm{Cd})_{\text {total }}$ & $\mathrm{mg} \mathrm{kg}^{-1}$ & 5,0 & 2,0 & 7,06 \\
\hline Chumbo $(\mathrm{Pb})_{\text {total }}$ & $\mathrm{mg} \mathrm{kg}^{-1}$ & 76 & 36 & 220 \\
\hline Cromo $(\mathrm{Cr})_{\text {total }}$ & $\mathrm{mg} \mathrm{kg}^{-1}$ & 526 & 49 & 497 \\
\hline Níquel $(\mathrm{Ni})_{\text {total }}$ & $\mathrm{mg} \mathrm{kg}^{-1}$ & 141 & 241 & 389 \\
\hline
\end{tabular}

Método empregado para os metais pesados: SW 3051, EPA U.S, determinação por ICP-AES. Todos os valores de concentração são dados com base na matéria seca.

Cerne, Lavras, v. 20, n. 2, p. 311-320, abr./jun. 2014 
$5^{\mathrm{a}}$ - água destilada, para a retirada do EDTA em contato com a amostra.

Após a lavagem, as amostras foram secadas em estufa de ventilação forçada a $60^{\circ} \mathrm{C}$. Em seguida, foram excluídas manualmente as raízes maiores que $5 \mathrm{~mm}$ de diâmetro, mortas ou de outras espécies de plantas (ex. daninhas). Foi considerada como morta a raiz que se apresentasse quebradiça e com coloração preta. As raízes resultantes da separação foram pesadas em balança eletrônica com precisão de $0,01 \mathrm{~g}$ e, posteriormente, submetidas à análise química, conforme Malavolta et al. (1989).

Os resultados foram primeiramente verificados quanto à necessidade de transformação dos dados, em seguida, foram submetidos à análise de variância e as médias foram comparadas pelo teste de Tukey a $5 \%$ de probabilidade. O software estatístico utilizado foi o SAS 9.1 for Windows (STATISTICAL ANALYSIS SYSTEM INSTITUTE - SAS INSTITUTE, 2003).

\section{RESULTADOS E DISCUSSÃO}

\subsection{Biomassa de raízes finas}

As árvores de E. grandis adubadas com lodo de esgoto, independentemente da ETE de origem, produziram em média 2,0 g de raízes finas(base seca) por $\mathrm{dm}^{3} \mathrm{de}$ solo, ao passo que no tratamento testemunha, a produção média foi de $1,6 \mathrm{~g} \mathrm{dm}^{-3}$. Ainda assim, não foram constadas diferenças significativas entre os tratamentos com lodo de esgoto e o tratamento testemunha (Figura 1).

Por outro lado, a biomassa de raízes finas produzida no tratamento LP foi significantemente superior (cerca de $70 \%$ ) em relação à biomassa do tratamento com fertilização mineral (FM). Com base nesses resultados, estima-se que a produção de raízes finas na camada de $0-20 \mathrm{~cm}$ do solo, nas linhas de plantio, variou de $2.800 \mathrm{~kg} \mathrm{ha}^{-1}$ (tratamento FM) a $4.600 \mathrm{~kg} \mathrm{ha}^{-1}$ (tratamento LP). A adubação com lodo de esgoto pode, muitas vezes, melhorar a porosidade e a capacidade de retenção de água do solo (VEGA et al., 2005) bem como aumentar a sua atividade microbiana (COLODRO et al., 2007) que, consequentemente, favorecem a produção de raízes finas pelas plantas.

Segundo Berton e Nogueira (2010), a adubação com lodos estabilizados com cal tendem a elevar o $\mathrm{pH}$ do solo e a reduzir a sua acidez potencial; principalmente, por ocasionar a precipitação do alumínio. Por isso, a produção de raízes finas no tratamento LP pode ter sido favorecida pela menor disponibilidade de $\mathrm{Al}^{3+}$ no solo $\left( \pm 4 \mathrm{mmol}_{c} \mathrm{dm}^{-3}\right)$, comparado aos demais tratamentos onde a concentração de $\mathrm{Al}^{3+}$ variou de 10 a $20 \mathrm{mmol}_{\mathrm{c}} \mathrm{dm}^{-3}$ (FERRAZ, 2009). Segundo Zonta et al. (2006), o alumínio $\left(\mathrm{Al}^{3+}\right)$, quando em contato com as raízes, promove rapidamente a paralisação do seu crescimento, tornando-as atrofiadas em função da morte ou injúria do meristema radicular.

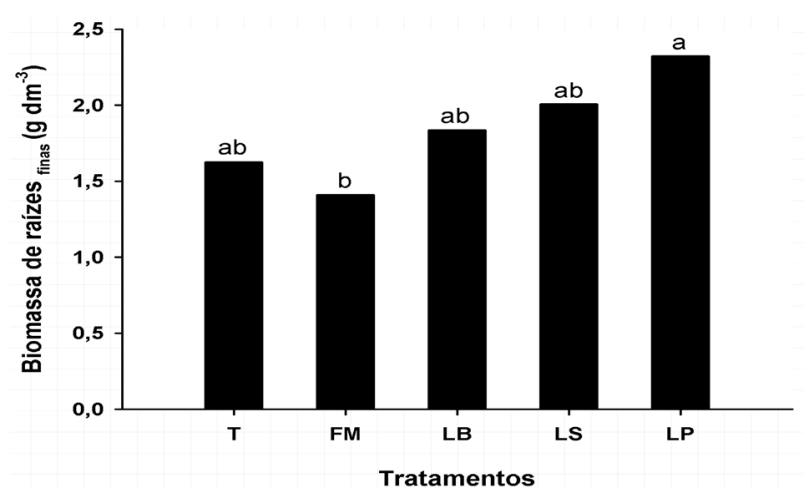

Figura 1 - Biomassa seca de raízes finas de E. grandis, coletadas na camada de $0-20 \mathrm{~cm}$ do solo, produzidas nos tratamentos: Testemunha (T), Fertilização mineral (FM), Lodo ETE Barueri (LB), Lodo ETE São Miguel (LS) e Lodo ETE Parque Novo Mundo (LP). Médias seguidas de pelo menos uma mesma letra não diferem entre si pelo teste de Tukey $(\mathrm{P}>0,05)$.

Figure 1 - Dry biomass of the fine roots of E. grandis sampled in the 0-20 cm soil layer in the treatments: Control (T), Mineral fertilizer (FM), Sludge ETE Barueri (LB), Sludge ETE São Miguel (LS) and Sludge ETE Parque Novo Mundo (LP). Means followed same a letter not differ between itself by Tukey's test $(P>0,05)$.

\subsection{Concentração de nutrientes e metais pesados}

A concentração de nitrogênio $(\mathrm{N})$ nas raízes finas foi similar entre todos os tratamentos (Figura 2), apresentando valor médio de $8,7 \pm 1,0 \mathrm{~g} \mathrm{~kg}^{-1}$. Por outro lado, a concentração radicular de fósforo no tratamento LB $(0,80$ $\mathrm{g} \mathrm{kg}^{-1}$ ) foi significativamente superior (cerca de $100 \%$ ) em relação aos tratamentos T e FM. Isso pode ser atribuído à elevada quantidade de fósforo (cerca de $600 \mathrm{~kg} \mathrm{ha}^{-1}$ ) adicionada ao solo com a aplicação do lodo produzido pela ETE de Barueri-SP.

Laclau et al. (2000), ao estudarem a ciclagem de nutrientes um plantios clonais de Eucalyptus ssp. no Congo, constataram que as concentrações de $\mathrm{N}$ e $\mathrm{P}$ nas raízes finas $(\varnothing<0,5 \mathrm{~cm})$ foram de 4,5 e $0,90 \mathrm{~g} \mathrm{~kg}^{-1}$, respectivamente.

Cerne, Lavras, v. 20, n. 2, p. 311-320, abr./jun. 2014 
Segundo esses autores, a concentração dos nutrientes e o seu acúmulo nos diferentes compartimentos dos eucaliptos (e.x. raízes) podem variar com a idade das árvores, com o tipo de clone e com a fertilidade do solo.

As concentrações radiculares de cálcio $(\mathrm{Ca})$ nos tratamentos $\mathrm{LB}, \mathrm{FM} \mathrm{e} \mathrm{T}$ foram significativamente inferiores (até 12 vezes menores) em comparação às concentrações observadas nas raízes de $E$. grandis produzidas nos tratamentos LS e LP. Esse resultado pode ser atribuído à elevada concentração de cálcio nos lodos de São Miguel e Parque N. Mundo (Tabela 2) decorrente da descarga de resíduos industriais (ricos em $\mathrm{Ca}_{2} \mathrm{SO}_{4}$ ) na rede coletora de
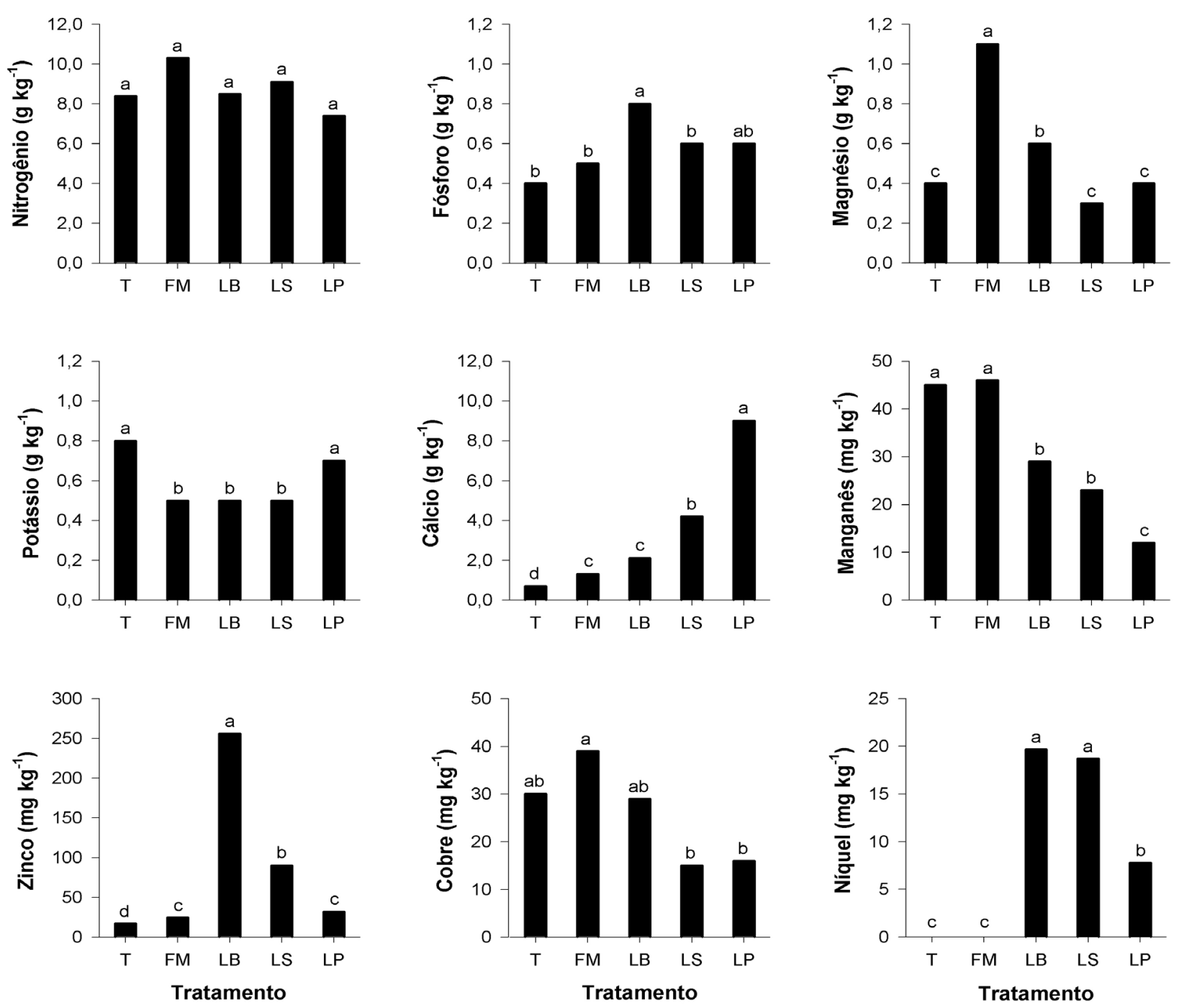

Figura 2 - Concentração de nutrientes e metais pesados nas raízes finas de E. grandis, nos tratamentos: Testemunha (T), Fertilização mineral (FM), Lodo ETE Barueri (LB), Lodo ETE São Miguel (LS) e Lodo ETE Parque Novo Mundo (LP). Para cada nutriente ou metal pesado, médias seguidas de pelo menos uma mesma letra não diferem entre si pelo teste de Tukey $(\mathrm{P}>0,05)$.

Figure 2 - Concentration of nutrients and heavy metals in fine roots of E. grandis, in the treatments: Control (T), Mineral fertilizer (FM), Sludge ETE Barueri (LB), Sludge ETE São Miguel (LS) and Sludge ETE Parque Novo Mundo (LP). For each nutrient or heavy metal, means followed same a letter not differ between itself by Tukey's test $(P>0,05)$.

Cerne, Lavras, v. 20, n. 2, p. 311-320, abr./jun. 2014 
esgoto ou em razão do tipo de condicionamento dado ao lodo nas diferentes estações de tratamento (adição de $\mathrm{CaO}$ ).

Observa-se, na Figura 2, que a concentração de magnésio $(\mathrm{Mg})$ nas raízes finas do tratamento FM foi significativamente superior (de 2 a 3 vezes maior) em comparação à testemunha e aos tratamentos com lodo de esgoto. Esse resultado pode ser atribuído à adição do calcário dolomítico ao solo, que, ao ser praticado no tratamento FM, possibilitou a correção da acidez do solo, o aumento da disponibilidade dos nutrientes, além de servir como fonte de magnésio (CAIRES, 2010).

Nos tratamentos FM, LB e LS, observa-se que a concentração de potássio $(K)$ nas raízes foi significativamente inferior à concentração observada nos tratamentos T e LP (Figura 2). Segundo Mills e Jones Junior (1996), a elevada mobilidade do potássio dentro da planta, atribuída à sua presença na forma iônica livre e à alta permeabilidade das membranas celulares a esse elemento, faz com que o K seja facilmente distribuído nos diferentes compartimentos da árvore (folhas, galhos, raízes etc.). Isso pode justificar a menor concentração de K nas raízes finas dos tratamentos em que as árvores de $E$. grandis apresentaram maior volume de madeira e biomassa aérea total, levando a um maior efeito-diluição desse elemento nos diferentes órgãos das plantas, conforme observado também por Gava (1997).

As concentrações radiculares de cobre $(\mathrm{Cu})$ nos tratamentos LP e LS foram significativamente inferiores em relação ao tratamento FM (em torno de 150\%), assim como as concentrações de manganês (Mn) foram menores nos tratamentos com lodo de esgoto se comparados aos tratamentos T e FM (até $280 \%$ menor). Segundo Dechen e Nachtigall (2006), o cobre e o manganês apresentam alta afinidade pela matéria orgânica do solo e, normalmente, tornam-se indisponíveis para as plantas. Conforme a tabela 2, os três lodos de esgoto apresentavam elevados teores de matéria orgânica em sua composição, o que pode ter contribuído para a complexação dos metais com as partículas do solo.

A concentração radicular de zinco $(\mathrm{Zn})$ no tratamento $\mathrm{LB}$ foi cerca de 3 a 100 vezes superior à concentração de $\mathrm{Zn}$ nos demais tratamentos testados. Segundo Kabata-Pendias e Pendias (2001), a concentração de zinco na planta é diretamente proporcional à quantidade de $\mathrm{Zn}$ disponível na solução do solo. Neste trabalho, a aplicação do lodo de esgoto de Barueri-SP (tratamento LB) adicionou ao solo cerca de $50 \mathrm{~kg}$ de $\mathrm{Zn}$ por hectare, ou seja, até 7 vezes mais zinco comparado aos demais tratamentos com lodo
(10-20 kg ha'-1) ou com fertilização mineral $\left(7 \mathrm{~kg} \mathrm{ha}^{-1}\right)$. Além disso, o uso agrícola de determinados lodos de esgoto (ex. tratado com polímero) pode provocar aumento da acidez no solo (BEZERRA et al., 2002), promovendo maior disponibilidade dos elementos metálicos na solução do solo.

Geralmente, o acréscimo de zinco ao solo em decorrência da adubação com lodo de esgoto (ex. tratamento LB) pode ser atribuído, principalmente, ao descarte de resíduos industriais (ricos em metais pesados) na rede coletora de esgoto. Portanto, o correto gerenciamento dos resíduos de origem industrial é necessário para a sua adequada disposição final (NASCIMENTO; MOTHÉ, 2007), podendo assim estimular o uso agrícola do lodo de esgoto quando não contaminado por metais pesados.

As concentrações radiculares de cádmio $(\mathrm{Cd})$, cromo $(\mathrm{Cr})$ e chumbo $(\mathrm{Pb})$ foram similares entre todos os tratamentos (Tabela 3). Nesse caso, as concentrações médias observadas nas raízes finas de E. grandis foram: 0,03 $\mathrm{mg} \mathrm{kg}^{-1}$ de Cd; $2,12 \mathrm{mg} \mathrm{kg}^{-1}$ de Cr e $0,81 \mathrm{mg} \mathrm{kg}^{-1}$ de $\mathrm{Pb}$. Mesmo contendo metais pesados em sua composição química, a adição dos lodos de esgoto ao solo não alterou significativamente a concentração de $\mathrm{Cd}, \mathrm{Cr}$ e $\mathrm{Pb}$ nas raízes finas das árvores.

Segundo Kabata-Pendias e Pendias (2001), os principais sintomas observados nas raízes em decorrência

Tabela 3 - Concentração de cromo (Cr), níquel (Ni), chumbo $(\mathrm{Pb})$ e cádmio $(\mathrm{Cd})$ nas raízes finas de E. grandis, nos tratamentos: Testemunha (T), Fertilização mineral (FM), Lodo ETE Barueri (LB), Lodo ETE São Miguel (LS) e Lodo ETE Parque Novo Mundo (LP).

Table 3 - Concentration of chrome ( $\mathrm{Cr}$ ), nickel (Ni), lead $(\mathrm{Pb})$ and cadmium $(C d)$ in fine root of E. grandis, in the treatments: Control (T), Mineral fertilizer (FM), Sludge ETE Barueri (LB), Sludge ETE São Miguel (LS) and Sludge ETE Parque Novo Mundo (LP).

\begin{tabular}{|c|c|c|c|c|}
\hline \multirow{2}{*}{ Tratamento } & $\mathrm{Cr}$ & $\mathrm{Ni}$ & $\mathrm{Pb}$ & Cd \\
\hline & \multicolumn{4}{|c|}{ - $\left(\mathrm{mg} \mathrm{kg}^{-1}\right)-$} \\
\hline $\mathrm{T}$ & $1,35 \mathrm{a}$ & $0,00 \mathrm{c}$ & $0,96 \mathrm{a}$ & $0,00 \mathrm{a}$ \\
\hline FM & $1,47 \mathrm{a}$ & $0,00 \mathrm{c}$ & $0,47 \mathrm{a}$ & $0,00 \mathrm{a}$ \\
\hline LB & $2,67 \mathrm{a}$ & $19,65 \mathrm{a}$ & $1,61 \mathrm{a}$ & $0,10 \mathrm{a}$ \\
\hline LS & $2,67 \mathrm{a}$ & $18,72 \mathrm{a}$ & $0,77 \mathrm{a}$ & $0,05 \mathrm{a}$ \\
\hline LP & $2,45 \mathrm{a}$ & $7,76 \mathrm{~b}$ & $0,23 \mathrm{a}$ & $0,01 \mathrm{a}$ \\
\hline
\end{tabular}

Para cada metal pesado (coluna), médias seguidas de pelo menos uma mesma letra não diferem entre si pelo teste de Tukey $(\mathrm{P}>0,05)$.

Cerne, Lavras, v. 20, n. 2, p. 311-320, abr./jun. 2014 
da toxidez por metais pesados são: redução do crescimento radicular, surgimento de raízes atrofiadas e de coloração marrom escuro. No entanto, esses sintomas não foram observados nas raízes amostradas em cada tratamento.

Por outro lado, a concentração radicular de níquel (Ni) em todos os tratamentos com lodo de esgoto foi significativamente superior em relação aos tratamentos T e FM (Figura 2). Para os tratamentos T e FM, não foi possível determinar a concentração radicular de $\mathrm{Ni}$, por estar abaixo do limite de detecção do equipamento analítico utilizado $\left(>0,01 \mathrm{mg} \mathrm{kg}^{-1}\right)$.

Nos tratamentos LB e LS, a concentração radicular de $\mathrm{Ni}\left(\right.$ média $=19 \mathrm{mg} \mathrm{kg}^{-1}$ ) foi aproximadamente 2,5 vezes maior comparada ao tratamento LP. O resultado está em consonância com os teores de Ni constatados nos diferentes lodos de esgoto (Tabela 2). Todavia, em nenhum desses tratamentos foram observados sintomas de toxidez por $\mathrm{Ni}$, como por exemplo: raízes finas bifurcadas, curtas, grossas e/ou quebradiças, conforme relatado por Paiva et al. (2000).

\section{CONCLUSÕES}

A biomassa de raízes finas produzida pelas árvores de Eucalyptus grandis foi similar entre os plantios adubados com os diferentes lodos de esgoto e o plantio sem qualquer adubação.

Em contrapartida, a adubação das árvores de E. grandis com o lodo previamente condicionado com $\mathrm{CaO}$ e $\mathrm{FeCl}_{3}$ propiciou maior biomassa de raízes finas se comparada à adubação com fertilizante mineral NPK.

De maneira geral, a adição dos lodos de esgoto ao solo elevou a concentração de $\mathrm{P}, \mathrm{Ca}, \mathrm{Zn}$ e Ni nas raízes finas de E. grandis e reduziu a concentração de $\mathrm{Mn}$, mas não alterou significativamente a concentração dos metais $\mathrm{Cd}, \mathrm{Cr}$ e $\mathrm{Pb}$ em relação às árvores sem qualquer adubação.

\section{AGRADECIMENTOS}

Ao Conselho Nacional de Desenvolvimento Científico e Tecnológico - CNPq (Processo n ${ }^{\circ}$ 130152/2009-

9) e a Fundação de Amparo à Pesquisa do Estado de São Paulo - FAPESP (Processo $n^{\circ}$ 2010/00706-2) pelas bolsas de mestrado e doutorado ao primeiro autor, respectivamente. Ao departamento de Ciências Florestais da Escola Superior de Agricultura "Luiz de Queiroz" / USP e ao Instituto de Pesquisas e Estudos Florestais - IPEF pelo auxílio concedido e aos funcionários Rildo Moreira e Moreira, António Leite de Moraes, Daniel dos Santos Fernandes e António Galvão de Oliveira pela colaboração na condução do experimento.

\section{REFERÊNCIAS}

ASSUNÇÃO, J. C. B.; SÍGOLO, J. B. Influência do ambiente tropical em lodos gerados na estação de tratamento de esgotos de Barueri, SP: comportamento dos metais pesados. Revista Brasileira de Geociências, São Paulo, v. 27, n. 4, p. 355-364, 1997.

BERTON, R. S.; NOGUEIRA, T. A. R. Uso de lodo de esgoto na agricultura. In: COSCIONE, A. R.; NOGUEIRA, T. A. R.; PIRES, A. M. M. (Org.). Uso agrícola de lodo de esgoto. Botucatu: FEPAF, 2010. p. 31-50.

BEZERRA, F. B.; OLIVEIRA, M. A. C. L. de; PEREZ, D. V.; ANDRADE, A. G. de; MENEGUELLI, N. do A. Lodo de esgoto em revegetação de área degradada. Pesquisa Agropecuária Brasileira, Brasília, v. 41, n. 3, p. 469-476, mar. 2002.

BOEIRA, R. C.; LIGO, M. A. V.; DYNIA, J. F. Mineralização de nitrogênio em solo tropical com lodos de esgoto. Pesquisa Agropecuária Brasileira, Brasília, v. 37, n. 11, p. 1639-1647, nov. 2002.

BORGES, M. R.; COUTINHO, E. L. M. Metais pesados do solo após aplicação de biossólido: II., disponibilidade. Revista Brasileira de Ciência do Solo, Viçosa, v. 28, n. 3, p. 557-568, 2004.

CAIRES, E. F. Manejo da acidez do solo. In: PROCHNOW, L. I.; CASARIN, V.; STIPP, S. R. (Ed.). Boas práticas para uso eficiente de fertilizantes. Piracicaba: International Plant Nutrition Institute, 2010. v. 1 , p. 277-347.

CAMARGO, O. A.; MONIZ, A. C.; JORGE, J. A.; VALADARES, J. M. A. S. Método de análise química, mineralógica e física de solos do Instituto Agronômico de Campinas. Campinas: Instituto Agronômico, 1986. 94 p. (Boletim Técnico, 106).

COLODRO, G.; ESPÍNDOLA, C. R.; CASSIOLATO, A. M. R.; ALVES, M. C. Atividade microbiana em um Latossolo degradado tratado com lodo de esgoto. Revista Brasileira de Engenharia Agrícola e Ambiental, Campina Grande, v. 11, n. 2, p. 195-198, 2007.

Cerne, Lavras, v. 20, n. 2, p. 311-320, abr./jun. 2014 
COMPANHIA DE TECNOLOGIA DE SANEAMENTO AMBIENTAL. Norma técnica P 4.230: aplicação de lodos de sistemas de tratamento biológico em áreas agrícolas: critérios para projeto e operação. São Paulo, 1999. 33 p.

DECHEN, A. R.; NACHTIGALL, G. R. Micronutrientes. In: FERNANDES, M. S. (Ed.). Nutrição mineral de plantas. Viçosa, MG: Sociedade Brasileira de Ciência do Solo, 2006. p. 327-354.

\section{EMPRESA BRASLEIRA DE PESQUISA}

AGROPECUÁRIA. Centro Nacional de Pesquisa de Solos. Sistema brasileiro de classificação de solos. 2. ed. Rio de Janeiro, 2006. 306 p.

FERRAZ, A. V. Ciclagem de nutrientes e metais pesados em plantios de Eucalyptus grandis adubados com lodos de esgoto produzidos em diferentes estações de tratamento da região metropolitana de São Paulo. 2009. 120 p. Dissertação (Mestrado em Recursos Florestais/Conservação de Ecossistemas Naturais) - Escola Superior de Agricultura "Luiz de Queiroz", Piracicaba, 2009.

GAVA, J. L. Efeito de adubação potássica em plantios de E. grandis conduzidos em segunda rotação em solos com diferentes teores de potássio trocável. IPEF, Piracicaba, v. 11, n. 30, p. 89-94, 1997.

GONÇALVES, J. L. de M.; MELLO, S. L. de M. O sistema radicular das árvores. In: GONÇALVES, J. L. de M.; BENEDETTI, V. (Org.). Nutrição e fertilização florestal. Piracicaba: IPEF, 2005. p. 219-267.

GUEDES, M. C.; ANDRADE, C. A. de; POGGIANI, F.; MATTIAZZO, M. E. Propriedades químicas do solo e nutrição do eucalipto em função da aplicação de lodo de esgoto. Revista Brasileira de Ciência do Solo, Viçosa, v. 30, n. 2, p. 267-280, 2006.

KABATA-PENDIAS, A.; PENDIAS, H. Trace elements in soils and plants. 3rd ed. Boca Raton: CRC, 2001. $413 \mathrm{p}$.

LACLAU, J. P.; BOUILLET, J. P.; RANGER, J. Dynamics of biomass and nutrient accumulation in a clonal plantation of Eucalyptus in Congo. Forest Ecology and Management, Amsterdam, v. 128, n. 3, p. 181-196, 2000.

MAGESAN, G. N.; WANG, H. Application of municipal and industrial residuals in New Zealand forests: an overview. Australian Journal of Soil Research, Melbourne, v. 41, p. 557-569, 2003.

MALAVOLTA, E.; VITTI, G. C.; OLIVEIRA, S. A. de. Avaliação do Estado nutricional das plantas: princípios e aplicações. Piracicaba: Associação Brasileira para Pesquisa da Potassa e do Fosfato, 1989. $201 \mathrm{p}$.

MILLS, H. A.; JONES JUNIOR, J. B. Plant analysis handbook II: a pratical sampling, preparation, analysis, and interpretation guide. Athenas: MicroMacro, 1996. 321 p.

NASCIMENTO, T. C.; MOTHÉ, C. G. Gerenciamento de resíduos sólidos industriais. Revista Analytica, Rio de Janeiro, v. 27, p. 36-48, 2007.

OLIVER, I. W.; MCLAUGHLIN, M. J.;

MERRINGTON, G. Temporal trends of total and potentially available element concentrations in sewage biosolids: a comparison of biosolid surveys conducted 18 years apart. Science of the Total Environment, Amsterdam, v. 337, n. 1/3, p. 139-145, 2005.

PAIVA, H. N.; CARVALHO, J. G.; SIQUEIRA, J. O. Efeito de $\mathrm{Cd}, \mathrm{Ni}, \mathrm{Pb}$ e $\mathrm{Zn}$ sobre mudas de cedro (Cedrela fissilis Vell.) e de ipê-roxo (Tabebuia impetiginosa Mart. Standley) em solução nutritiva. Revista Árvore, Viçosa, v. 24, n. 4, p. 369-378, set./out. 2000.

RAIJ, B. van; QUAGGIO, J. A.; CANTARELLA, H. Análise química do solo para fins de fertilidade. Campinas: Fundação Cargill, 1987. 170 p.

ROBINSON, D. Implications of a large global root biomass for carbon sink estimates and for soil carbon dynamics. Proceedings of the Royal Society Biological Science, London, v. 274, p. 2753-2759, 2007.

ROCHA, G. N.; GONÇALVES, J. L. M.; MOURA, I. M. Mudanças da fertilidade do solo e crescimento de um povoamento de Eucalyptus grandis fertilizado com biossólido. Revista Brasileira de Ciência do Solo, Viçosa, v. 28, n. 4, p. 623-639, 2004.

SOARES, C. R. F. S.; SIQUEIRA, J. O.; CARVALHO, J. G.; MOREIRA, F. M. S.; GRAZZIOTTI, P. H. Crescimento e nutrição de Eucalyptus maculata e Eucalyptus urophylla em solução nutritiva com concentração crescente de cobre. Revista Brasileira de Fisiologia Vegetal, Campinas, v. 12, n. 3, p. 213-225, 2000.

Cerne, Lavras, v. 20, n. 2, p. 311-320, abr./jun. 2014 
STATISTICAL ANALYSIS SYSTEM INSTITUTE. SAS user's guide: statistics. Cary, 2003.

VEGA, F. V. A.; BOVI, M. L. A.; BERTON, R. S.; GODOY JUNIOR, G.; CEMBRANELLI, M. de A. R. Aplicação de biossólido na implantação da cultura da pupunheira. Horticultura Brasileira, Brasília, v. 22, n. 1, p. 131-135, 2004.

VEGA, F. V. A.; BOVI, M. L. A.; GODOY JUNIOR, G.; BERTON, R. S. Lodo de esgoto e sistema radicular de pupunheira. Revista Brasileira de Ciência do Solo, Viçosa, v. 29, n. 2, p. 259-268, 2005.

WITSCHORECK, R.; SCHUMACHER, M. V.; CALDEIRA, M. V. W. Estimativa da biomassa e do comprimento de raízes finas em Eucalyptus urophylla S. T. Blake no município de Santa Maria, RS. Revista Árvore, Viçosa, v. 27, n. 2, p. 177-183, 2003.

ZONTA, E.; BRASIL, F. C.; GOI, S. R.; ROSA, M. M. T. O sistema radicular e suas interações com o ambiente edáfico. In: FERNANDES, M. S. (Ed.). Nutrição mineral de plantas. Viçosa: Sociedade Brasileira de Ciência do Solo, 2006. p. 7-52.

Recebido: 14 de março de 2012; aceito: 26 de setembro de 2013. 
